\title{
DE LA SUPERVIVENCIA DE LOS INEPTOS A LA RUINA DE LAS NACIONES: TRADUCCIONES ESPAÑOLAS DE DAVID STARR JORDAN, PRIMER RECTOR DE STANFORD
}

\author{
J.J. LANERO \\ Universidad de León
}

\begin{abstract}
Resumen
El Dr. Jordan, Rector de la Universidad de Indiana, durante seis años, y primero de la de Stanford, durante unos veinticinco, con más de cincuenta libros y 1.000 artículos publicados, no necesita de presentación entre los botánicos y los zoólogos especialistas en ictiología. Lo que llama la atención es que mereciera la atención del traductor castellano no por esos estudios, sino por dos obras: La cosecha humana (1912) y El imperio invisible (1914); en la primera Jordan estudia el efecto de las guerras en la raza humana y en la segunda, el empobrecimiento de los pueblos por causa de los enfrentamientos bélicos. No ha de olvidarse que, precisamente en aquel 1914, comenzó la sangrienta I Guerra Mundial. El traductor de ambos libros fue un prolífico hispanista: Aurelio Macedonio Espinosa, fundador de los estudios hispánicos en la Universidad de Stanford. En el presente estudio intentamos abordar el por qué y el para qué de estas dos traducciones, cercanas a la aparición de los textos originales y referencias casi únicas del "Dr. Jordán" en España y América Latina.
\end{abstract}

Palabras clave: Darwinismo; guerra; economía.

\begin{abstract}
Dr. Jordan, President of Indiana University for six years and first President of Stanford University for twenty five, with more than fifty books and 1.000 papers, needs no introduction among botanists and zoologists specialised in ictiology. The Spanish translator did not pay attention to any of those works but rather to The Human Harvest (1912) and Unseen Empire (1914). In the former, Jordan studies the war effects on humanity and in the latter, the countries' impoverishment due to war confrontations. One should not forget that in that year of 1914 the bloody First World War started.The translator of both books was Aurelio Macedonio Espinosa founder of the Department of Spanish Studies at Stanford University. In the present paper we are trying to find out why and for whom Espinosa translated these two works shortly after they were first published in English and being the only references to Dr. Jordan both in Spain and Latin America.
\end{abstract}

Key words: Darwinism; war; economics.

El pasado año 2001 se cumplió el 150 aniversario del nacimiento de David Starr Jordan y el septuagésimo de su muerte. Desde entonces, ha recibido escasa o nula atención, tan sólo para recordar lo que ni siquiera es necesario: su prestigio en los campos de la botánica y de la ictiología. La Universidad de Stanford lo recuerda por haber sido su primer Presidente, que nosotros traducimos como Rector, durante veintidós años, desde su fundación por Leland Stanford, Jr.

Jordan, como todos, fue fruto de su tiempo, de su entorno y del legado cultural estadounidense. En sus ideas políticas recibió la influencia, entre otros, 
de Henry David Thoreau, a pesar de que este asceta de Concord tuviera aspectos en su pensamiento que el Rector de Stanford no estaba dispuesto a suscribir (Burns, 1953: 212), como el enfoque místico que Thoreau adoptaba ante la vida y el conocimiento. Para Jordan todo debía provenir de la inducción, de la experiencia y del poder de la razón. Por extensión, Jordan, como Thoreau, se vio influido por Ralph Waldo Emerson, al que citaba con frecuencia y en el que se inspiraba para titular sus libros y artículos. Podríamos llegar a decir que su estilo es muy similar al del sabio Emerson. Con él compartía su optimismo, su amor a la naturaleza, su filosofía económica y política. Ambos creían que el individuo es superior a la colectividad.

El pacifismo del Dr. Jordan está íntimamente relacionado con su concepto de economía política y su creencia en la supremacía de la ciencia. Cuando estalló la guerra de Cuba llegó a la conclusión de que la guerra era un despilfarro y que no existían beneficios que pudieran equilibrar la balanza. Como científico, le escandalizaban los efectos de la guerra en el deterioro de las naciones. En este sentido, las influencias que modelaron su pensamiento provenían de las obras de Charles Darwin y Yakov Kovikov; este último, sociólogo franco-ruso, seguidor del darwinismo social. En 1911, Jordan, tras leer su libro War and Its Alleged Benefits, persuadió a Henry Holt para que publicara una traducción en Estados Unidos (Booth y Wright, 1978).

Por lo demás, este hombre que a lo largo de su vida publicó más de cincuenta libros y mil artículos (Hays, 1952) tomó ideas de casi todo el mundo. Desde Cicerón a Herbert Hoover. Y, además de los ya citados, reconoció en Lincoln al defensor de la libertad y del respeto por los demás; en John Morley y William James, su oposición al imperialismo; en Charles Peirce y John Dewey, las raíces de su filosofía. Y con frecuencia citaba a John Milton, Matthew Arnold, Thomas Carlyle, John Stuart Mill, John Bright, William Graham Sumner, Oliver Wendell Holmes, Goldwin Smith y George William Curtis.

El lugar que corresponde a David Starr Jordan en la historia del pensamiento político y social y el valor de sus aportaciones serán siempre un tema controvertido. John Burns, notable personalidad política de la Inglaterra de principios de siglo, después de leer Human Harvest, comentó a Jordan que estaba decidido a no entrar nunca en ninguna guerra, con independencia de su propósito, pues las repercusiones en la población inglesa serían terriblemente desastrosas (Jordan, 1922: II, 639). Burns cumplió su promesa en 1914 cuando dimitió de su cargo de ministro del gabinete británico antes de apoyar la propuesta de una declaración de guerra. Jordan fue un pionero de la política de buena vecindad que más tarde haría suya el Presidente F.D. Roosevelt y que implicaba la renuncia al derecho a intervenir, la condena del imperialismo político y económico, la reafirmación de responsabilidad conjunta para repeler las agresiones y la ampliación del panamericanismo en solidaridad hemisférica. Reactivó la vieja doctrina de Jefferson y Emerson de que la función principal del estado es formar personas, por lo que instó a una estrecha cooperación entre el gobierno y las universidades. Defendió la importancia del autogobierno y del valor de la libertad como garante de la confianza en uno mismo. Expuso mejor que nadie las verdaderas causas de las guerras, que no son sólo económicas, 
pues son la base de la existencia misma de las naciones soberanas que obran siguiendo la teoría de que cada uno tiene que representar el papel de una hiena rodeada por una manada de lobos.

Jordan fue uno de los pocos americanos que rechazó el darwinismo social en favor de la idea de que el altruismo es una parte tan importante de la naturaleza humana como el egoísmo. Llegó a preguntarse si el principio del amor no era la clave del universo. A pesar de todo lo dicho, Jordan intentó abarcar demasiados campos: profeta de la paz y de la democracia, científico, educador, economista político, filósofo de la religión y de la ética. Esta lucha por la universalidad le condujo a errores tan graves como la aceptación del arianismo y la asunción de que los anglosajones representaban las virtudes puritanas que otros pueblos ni siquiera podían soñar en tener: diligencia, frugalidad, sobriedad y éxito. En su descargo hay que decir que, en su tiempo, el mito racial formó parte del bagaje intelectual de muchos americanos.

Quizá el aliento se nos contiene con las anteriores palabras, que llevadas a su máxima expresión, condujeron a la lamentable creación del nacional-socialismo y de cuyas repercusiones todavía no se ha resarcido el mundo. Ahora bien: en Jordan primaban más las virtudes antedichas que la raza en sí; no en vano admiró también el tesón de los japoneses.

\section{2}

Sería laborioso, además de interminable, ofrecer aquí una breve sinopsis de todo cuanto Jordan escribió. Nos bastará con referirnos a los textos que, posteriormente se tradujeron al español.

Así, en 1907, se publicó The Human Harvest. El título se completa con una perorata sorprendente: ... A Study of the Decay of Races Through the Survival of the Unfit... (Jordan, 1907a). En este libro se recoge el espíritu de dos ensayos anteriores. Uno es una conferencia pronunciada en la Universidad de Stanford en 1899, impresa en 1902 por la American Unitarian Association con el nombre de The Blood of the Nation (Jordan, 1902). El otro ensayo lo expuso Jordan en el Segundo Centenario del nacimiento de Benjamin Franklin; se trata de "The Human Harvest" y apareció en las Proceedings of the American Philosophical Society en 1906. Llama la atención que años más tarde, en 1915, publicó otro libro, War and the Breed: The Relation of War to the Downfall of Nations (Jordan, 1915). En la "Prefactory Note", confirmando lo que había dicho y publicado, afirma:

This book is written to show the relation of war to the downfall of nations. The certainty that war leads to radical decadence by obliteration of the most virile elements, these being thereby left unrepresented in heredity, is becoming widely accepted as the crucial argument against the war system of the world, standing second only to the final argument of the human conscience that murder remains murder ever when done on a gigantic scale under the sanction of the state and the blessing of the church (...). The same topic is treated in two previous essays (...). The present volume ha been entirely rewritten (Jordan, 1915). 
El contenido de The Human Harvest, en toda su extensión, título completo incluido, no deja de estremecer al lector español, al latinomediterráneo y al latinoamericano. Jordan identificaba la superioridad de la raza con la posesión de cualidades tales como estabilidad, resolución, autocontrol, abstinencia, eficacia, iniciativa y frugalidad. Eran virtudes puritanas disociadas de su origen teológico; eran las que habían hecho posible el desarrollo y el mantenimiento de la república americana; ninguna otra puede servir de fundamento para el idealismo, el sacrificio y la devoción por el poder, todos ellos componentes esenciales del buen ciudadano; eran las virtudes de Washington, Emerson, Thoreau, John Brown y Lincoln; eran las únicas que podían hacer grande a una nación en términos de justicia, estabilidad, libertad y orden. Para Jordan una sociedad ordenada dependía de una rigurosa operación de proceso biológico referido a la selección natural. La ley del más fuerte significaba la eliminación del disoluto y holgazán.

En 1912, contando con el sistema que era habitual en todas las obras de Jordan (primero la conferencia, luego el ensayo y finalmente el libro), se publicó Unseen Empire, A Study of the Plight of Nations That Do Not Pay Their Debts (Jordan, 1912a). Inicialmente, había sido un discurso pronunciado en Honolulu el año anterior, 1911, y publicado en Diciembre de ese mismo año en Mid-Pacific Magazine. Podría decirse que es una obra en defensa del pacifismo; un pacifismo basado en los gastos que suponen las guerras y el enriquecimiento de los prestamistas, que Jordan agrupa en ese Unseen Empire del título. De forma sospechosa, el autor piensa que el dinero está en manos de los judíos. Si unimos este dato con los que se desprenden de la obra anterior, parece que las conclusiones sobre la forma de pensar de Jordan son fáciles de extraer.

Con estos antecedentes, sorprende que estas obras fueran traducidas al español. Ambas lo fueron por la mano del mismo traductor: Aurelio Macedonio Espinosa, fundador de los estudios hispánicos en la Universidad de Stanford. Había nacido en 1880 en una zona rural fronteriza entre los estados de Colorado y Nuevo México, en el seno de una familia humilde. Se doctoró en la Universidad de Chicago. Algunas de sus obras se han seguido publicando incluso después de su muerte en 1958 (Espinosa, 1985); otras alcanzaron una notoria difusión: El Romancero Español: sus orígenes y su historia en la literatura universal (1931) y Romancero de Nuevo México (1953). Espinosa, hasta donde hemos podido averiguar, era un ferviente católico que no dudó en expresar sus simpatías por Franco al estallar la guerra civil española. Sería disparatado tratar de unir aquí racismo, políticas filofascistas y religión. No obstante, si intentamos llegar a saber las razones que llevaron a Espinosa, que con toda seguridad no pertenecía a la raza que preconizaba Jordan, a traducir estas dos obras del Rector de Stanford, que a su vez tampoco tenía nada que ver con el credo religioso de Espinosa, cabría preguntarse qué otro vínculo pudo unirlos, descartadas raza y religión. Alguien podría sugerir que las ideas políticas. Y esas son aguas todavía más turbias que las anteriores. Jordan creía en la superioridad de las virtudes del anglosajón, pero no hasta el extremo de llegar a 
simpatizar con grupos radicales y violentos. Lo mismo puede decirse de Espinosa, al que la intervención franquista le pareció bien desde la lejanía. Con todo, en esencia, solo que invocando tradiciones diferentes, si no opuestas, podríamos tener un punto en el que ambos convergen. Quizá nunca lo supieron. Finalmente, quedaría otra razón para que Espinosa tradujera estas dos obras de Jordan; sería una tan sencilla como la lealtad que se le debe al jefe: Jordan, Rector de una universidad privada en la que Espinosa enseña una lengua moderna; un docente fiel dispuesto a complacer los deseos de su superior.

Con todo lo dicho, o a su pesar, puede que, desde orientaciones distintas, ambos estuvieran de acuerdo en el fondo. La historia está jalonada de contradicciones que, en un momento determinado, encuentran una sencilla explicación. Así, las obras de Jack London fueron lecturas recomendadas por el régimen del III Reich; del mismo modo, sus dirigentes no hicieron ascos a la hora de asociarse con regímenes similares en el pensamiento pero opuestos en lo tocante a principios raciales. Ahí tendríamos a los arios alemanes en sintonía con unos italianos latinos.

La traducción española de The Human Harvest se publicó en Madrid en 1912, cinco años después de su aparición en forma de libro en Boston. Se trata de un volumen, el cuarto, de la colección Biblioteca filosófico-sociológica. El título completo: La cosecha humana, estudio sobre la decadencia de las razas á causa de la supervivencia de los ineptos. Los nombres del autor y del traductor aparecen recogidos en la portada: David Starr Jordan, Presidente de la Universidad Leland Stanford Junior (California) y Aurelio Macedonio Espinosa, Profesor de la misma Universidad. No falta una cita de Novicow (sic), autor que Jordan había leído y que ejerció una notable influencia sobre él: "La guerre a produit de tout temps une selection à rebours" (Jordan, 1912b).

A nivel anecdótico, hay que señalar cómo la disposición tipográfica es la misma en el original y en el texto traducido: todas las páginas están enmarcadas y en el margen izquierdo o derecho, dependiendo de si es impar o par, un rectángulo en disposición vertical en el que se anuncia cada uno de los temas que componen el libro y que constituyen el índice. Un año antes, en 1911, se había publicado en París la traducción francesa, La Moisson humaine (Jordan, 1911a). Jordan, en su autobiografía The Days of a Man (Jordan, 1922: I, 619-20) hace alusión a las traducciones de sus obras. En una nota a pie de página se refiere a La Moisson humaine, traducida al francés por Jacques Dumas (?). Resulta sorprendente comprobar que la identidad del traductor que nos facilita Jordan no corresponde con el nombre que se recoge en la portada del librito francés, que dice ser trabajo de un tal A(lbert) L(eón) Guérard. La confusión tiene fácil respuesta: ambos lo tradujeron y los dos llegaron a conocerlo durante su visita a Francia. La traducción que Jordan adjudica a Dumas es un error. Éste solamente puso en francés "War and Manhood", "La Guerre et la virilité" (Jordan, 1911b: 11-2). Jordan también menciona la traducción alemana de esa obra, Krieg und Mannheit (Jordan, 1912c). Con La cosecha humana ocurre algo 
similar. En la referida nota, los datos que nos da Jordan son correctos. Lo declara "volumen complementario" (companion volume) de El imperio invisible, traducción que Espinosa hizo de su Unseen Empire. Hasta aquí todo correcto; pero en el índice de autores y temas, en el segundo volumen de su monumental autobiografía, se nos remite a la traducción de War and Breed al español, obra de Espinosa, que nunca se hizo (Jordan, 1922: II, 861) y, por lo tanto, no está documentada en la página a la que nos remite. También incluye a Kotumin no Kotto, traducción al japonés de The Blood of the Nation, realizada por I. Nakamura en 1907. Jordan comete un tercer error. El nombre del autor de la versión japonesa no corresponde a la inicial I, pues se llama Taira (Jordan, 1922: II, 620).

Es preciso recordar que The Human Harvest (1907) fue la conjunción de The Blood of the Nation (1902) y "The Human Harvest" (1906). El resultado final, The Human Harvest (1907), fue reelaborado a su vez dando lugar a War and the Breed. No es de extrañar, pues, que el mismo Jordan tomara a La cosecha humana como traducción de esa obra.

La labor traductora no debió ser tarea fácil para Espinosa, que "reordena" el texto origen en su texto meta; presenta un índice más escueto por haberse decidido por otro sistema de agrupación de encabezamientos. Mientras el texto original cuenta con un índice compuesto por sesenta y tres entradas, en el meta se resumen en treinta y nueve. Espinosa ejerce de censor; unas veces por dignidad personal, otras por prurito histórico y en algunas porque las referencias de Jordan a ciertos aspectos de la vida americana dejarían indiferente al lector español. Llegados al final del libro, el último capítulo de Jordan se titula "The Best Political Economy"; el de Espinosa se llama "Resumen". Pero volvamos sobre nuestras propias palabras: ¿es Espinosa un mero transmisor, un adaptador, o un censor? Un poco de todo. Los párrafos hablan por sí solos. Ambos terminan igual, si bien las líneas anteriores difieren por completo:

The remedy for most ills of men is not to be sought in "whirlwinds of rebellion that shake the world," but in peace and justice, equality among men, and the cultivation of those virtues we call Christian, because they have been virtues ever since man and society began, and will be virtues still when the era of strife is past, when false glory ceases to deceive, and when no longer

"The red coat bully in his boots

Shall hide the march of man from us"

It is the voice of political wisdom, the expression of the "best political economy," which falls from the bells of Christmas-tide: "Peace on earth, good will towards men!"
El mismo motivo y la misma advertencia se encuentran en todas las páginas de la historia, y todo lo resumen de un modo claro las palabras del sabio americano Benjamin Franklin:

"No se pagan las costas de las guerras mientras ellas duran, sino que el saldo viene después"

En una palabra: la suma del saber político, la declaración de la mejor economía política es la que repican las campanas de Noche Buena: "Paz en la tierra á los hombres de buena voluntad" (Jordan, 1907b: 122; Jordan, 1912b: 112). 
Es bastante probable que las palabras de Franklin le fueron pintiparadas como punto de engarce con la siguiente traducción que Espinosa pensaba ofrecer: ese volumen que el propio Jordan en su autobiografía definió como complementario del anterior. The Unseen Empire, según hemos visto, se publicó en 1912. Dos años más tarde, 1914, lo hacía la traducción española, El imperio invisible. Estudio sobre la bancarrota y ruina de las naciones a consecuencia de las guerras pasadas y futuras. -Causas y antecedentes de la actual guerra europea. Esta vez Espinosa, además de su propio prólogo solicitó otro al Doctor Modesto Hernández Villaescusa que, según la portada, había sido Rector y Catedrático de la Universidad de Oñate.

Modesto Hernández Villaescusa y Ros de Medina, alicantino de nacimiento, auspició un movimiento católico social en Gerona. En 1895 fue nombrado profesor de la Universidad de Oñate, que estaba sostenida por el Ayuntamiento de la ciudad y la Diputación provincial de Guipúzcoa, de la que fue Decano de la Facultad de Filosofía y Letras además de Vicerrector y Rector. También fue traductor; en 1900 publicó Judios y católicos en Austria-Hungría, de Kannengieser. De regreso a Barcelona, se dedicó por completo a escribir. Le nombraron director literario de la casa editorial católica Herederos de Juan Gili, de Barcelona, precisamente la que fue responsable de la versión española El imperio invisible. No sobra recordar aquí que la editorial mencionada se transformó posteriormente en Editorial Litúrgica Española. Hernández Villaescusa también compuso el devocionario litúrgico Luz y esperanza del alma ${ }^{1}$.

En su "Prólogo de la edición española" (Jordan, 1914), Hernández Villaescusa realiza afirmaciones rotundas desde su posición, por lo visto, de autoridad consagrada. Algunas desde el atrevimiento que le permite su ignorancia y otras que hubieran enfurecido al mismo Jordan. Sus apostillas sobre raza y religión no pueden pasar desapercibidas:

Con método positivo, frío, tangible, cual corresponde a un verdadero yanki, a un sajón de pura raza, estudia el Dr. David Starr Jordán una por una las diversas etapas que han conducido a las más poderosas naciones de Europa al terrible (...) conflicto social. Ese imperio invisible no es otro que la deuda nacional, deuda contraida con miras a la guerra. Paso a paso va describiendo el origen de ese imperio que radica en la ambición de la banca judía... (Jordan, 1914).

Y puestos a hablar, el prologuista se mete en mayores profundidades y alude a la civilización sin Dios, pagana y corrompida de aquellos años. De esa condena no se libra nadie, ni siquiera Jordan:

Sin ir más lejos, en esta misma obra no se habla una palabra de Dios ni de religión; se ignoran, o se finge ignorar, las causas sobrenaturales; todo se fía a la quebradiza virtualidad de los humanos medios y recursos (Jordan, 1914: 3).

Incita al lector a que saque enseñanzas de sus palabras, aun por encima de las de Jordan. Surge aquí una vieja controversia: cómo ha de traducirse una

\footnotetext{
${ }^{1}$ Enciclopedia universal ilustrada europeo-americana, Espasa-Calpe, S.A., Madrid, tomo XXVII, p. 1235.
} 
obra cuando el mensaje que se propone transmitir está tan relacionado con la religión, las ideologías y la política (Rose, 1995; Venuti, 1992). Porque puede que tengamos una buena traducción pero, si además se nos conceden unas claves para su lectura, la situación cambia por completo. Esos parecen ser los objetivos de Hernández Villaescusa, que adopta una postura de ideales místicos, olvidando quién es el autor y de qué cultura, entorno y tradición proviene:

Si de veras se quiere la paz, hay que volver, pues, los ojos (...) a Jesucristo Redentor, que trajo la paz a los hombres, y a su Iglesia santa, que predica la paz y el amor en todas las regiones de la tierra. Es esta la única paz verdadera, sólida, perdurable (Jordan, 1914: 4).

Por si el lector no ha quedado suficientemente instruido, a continuación se abre el "Prólogo del Traductor", en el que, cabría esperar, éste nos hablara de las dificultades encontradas y de cómo las ha solventado. Nada de eso. Espinosa comienza refiriéndose a los estudios de Jordan sobre la herencia y la evolución biológica y social. Menciona las traducciones de The Human Harvest a otros idiomas, y glosa su contenido incorporando citas de su propia traducción:

En La Cosecha Humana [Jordan] nos prueba que la razón principal de la decadencia de las razas europeas, se encuentra en la guerra, que destruye a lo más aptos y deja a los ineptos para padres de familia. "Cuando la nación envía a la destrucción lo mejor que cría, esto es, sus hijos nobles, valientes, fuertes, vienen los peores a llenar su puesto. Los débiles, los viciosos, los perezosos, se propagan y llenan la tierra" (Jordan, 1914: 7).

No parece que Espinosa, si se nos permite, se sienta incluido en el grupo de los débiles. De nuevo es oportuno subrayar que Jordan admiraba las virtudes del anglosajón. Pero de ahí a las iniciativas que otros tomaron, como nos enseña la historia, el trecho fue muy escaso. Y el traductor vivió para verlo.

Tampoco olvida Espinosa la alabanza al jefe: “... el Dr. Jordan (...) desempeña el cargo de Rector de la Universidad de Leland Stanford, cuyo nombre ha hecho célebre con su energía personal y elevadas ideas" (Jordan, 1914: 7).

El último párrafo le sirve para resumir lo que Jordan pretende decir en las 130 páginas siguientes:

... después de los estudios sobre los efectos de las guerras en cuanto a la herencia, quedaba por hacer otro (...) sobre los efectos no hereditarios del empobrecimiento del pueblo por el gasto de las guerras y de los preparativos para las guerras. Fruto de este estudio es la obra que sigue, El Imperio Invisible (Jordan, 1914: 8).

Da la impresión de que los ocho capítulos de que consta la obra, además de un Apéndice lleno de datos estadísticos, ya están suficientemente aclarados, sea el apartado "El poder del dinero" o "Cómo evitar el peligro de la guerra". 
¿Qué conclusiones pueden sacarse? Jordan no fue muy traducido. Es un hecho. Ni siquiera abundaron las ediciones británicas. Las versiones españolas, sin duda, destacan sobre todas las demás. Cierto que Espinosa no tuvo que hacer grandes esfuerzos para conocer las obras de su Rector; también es verdad que según parece, y en opinión de algún hispanista que llegó a tenerlo de compañero de Departamento, simpatizó con el golpe franquista por ser sinónimo de la recuperación de un pasado de gloria en el que raza, política y religión eran una amalgama.

Espinosa debió pensar que lo que Jordan decía del anglosajón y de sus virtudes, era aplicable a la herencia hispánica de la que él formaba parte. Y, de modo conveniente, adaptó las obras a ese concepto. Para su publicación, por ejemplo, prefirió España a cualquier otro país de lengua castellana. Era como una veneración de los orígenes, o la recuperación de los mismos. La cosecha humana formó parte de la Biblioteca filosófico-sociológica, encargada de poner en manos del lector selecto y de la intelectualidad del momento lo mejor y más granado de las letras mundiales. Así, el primer tomo de la colección fue $L a$ familia, de Pablo Janet, Profesor de la Facultad de Letras de París; el segundo, La soledad, del Dr. Zimmermann; el tercero, La escuela neutra, de Eugenio Cemborain; el cuarto fue el de Jordan.

Por lo que se refiere a El imperio invisible, la fecha justificaba por demás la traducción, su temática y lectura: la primera guerra mundial. Prologuista y traductor, conscientes de la actualidad, no dudaron en aliñar la obra con los principios en los que ellos creían con firmeza: la intervención de Dios; aunque la práctica religiosa que ambos observaban no coincidía con el legado puritano al que pertenecía Jordan, él mismo nada aficionado a ningún tipo de iglesia institucionalizada.

Ambas traducciones son obras de juventud de Espinosa, que no había cumplido los cuarenta cuando se publicaron. Jordan escribió muchas otras obras, pero ninguna más se tradujo al español. El porqué es pura incógnita.

Con todo, y por esta vez, el disfraz de tradición y religiosidad con el que vistieron al Jordan español, mereció la pena. ¡Cuánto ignoraban todos que la Variación, la Herencia, la Segregación y la Selección, que aparecen en La cosecha humana, iban a ser de nefastas consecuencias en el siglo XX!. Desde la perspectiva que nos conceden estos casi cien años de distancia, la recuperación de estas dos traducciones cobra valor por los acontecimientos posteriores.

\section{BIBLIOGRAFÍA}

Booth, K. y Wright, M. (1978): American Thinking About Peace and War, New York, Baines \& Noble.

Burns, E. M. (1953): David Starr Jordan: Prophet of Freedom, California, Stanford University Press.

Burrell, T. y Kelly, J. K. (Eds.) (1995): Translation: Religion, Ideology, Politics, State University of New York at Binghamton. 
Espinosa, A. M. (1985): The Folklore of Spain in the American Southwest: Traditional Spanish Folk Literature in Northern Mexico and Southern Colorado, Norman, University of Oklahoma Press.

Hays, A. N. (1952): David Starr Jordan: A Bibliography of His Writings, 1871-1931, California, Stanford University Press.

Jordan, D. S. (1902): The Blood of the Nation, a Study of the Decay of Races Through the Survival of the Unfit, American Unitarian Association.

Jordan, D. S. (1907a): The Human Harvest, A Study of the Decay of Races Through the Survival of the Unfit..., Boston, The Beacon Press.

Jordan, D. S. (1907b): The Human Harvest, London, Alston Rivers, Limited.

Jordan, D. S. (1911a): La Moisson humaine... Essai sur la décadence des races par suite de la survivance du moins apte..., traduit de l'anglais par A.L. Guérard, Paris, M. Giard \& E. Brière.

Jordan, D. S. (1911b): "La Guerre et la virilité", Traduit de l'anglais de War and Manhood, par Jacques Dumas, La Paix par le droit, 21: 1-12.

Jordan, D. S. (1912a): Unseen Empire, A Study of the Plight of Nations That Do Not Pay Their Debts, Boston, The Beacon Press.

Jordan, D. S. (1912b): La cosecha humana, estudio sobre la decadencia de las razas á causa de la supervivencia de los ineptos, Traducido del inglés por Aurelio Macedonio Espinosa, Madrid, Casa Editorial Bailly-Bailliere.

Jordan, D. S. (1912c): Krieg und Mannheit, berechtigte Übersetzung, Berlin, Verlag der "Friedens Wärte".

Jordán, D. S. (1914): El imperio invisible. Estudio sobre la bancarrota y ruina de las naciones a consecuencia de las guerras pasadas y futuras. -Causas y antecedentes de la actual guerra europea, Traducción del inglés por el Aurelio M. Espinosa, Prólogo de Modesto Hernández Villaescusa, Barcelona, Herederos de Juan Gili, Editores.

Jordan, D. S. (1915): War and the Breed: The Relation of War to the Downfall of Nations, Boston, The Beacon Press.

Jordan, D. S. (1922): The Days of a Man. Being Memories of a Naturalist, Teacher and Minor Prophet of Democracy, 2 vols., New York, World Book Company, Yorkers-onHudson.

Rose, M. G. (1995): “Religion and Translation: Innocence and Guilt” en Toldd Burrell y Jean K. Kelly (eds.) (1995).

Venuti, L. (Ed.) (1992): Rethinking Translation: Discourse, Subjectivity, Ideology, London, Routledge. 